\title{
Discurso $v s$. realidad en las campañas antichinas en Sonora (1899-1932)
}

\author{
Macrina Rabadán Figueroa* \\ EL COLEGIO DE MÉXICO
}

Se explora el contrastre entre la imagen de los chinos presentada en los discursos de las campañas en su contra y la integración real que esta población vivió en la sociedad sonorense.

$\mathrm{E}$ nel presente artículo me propon. go analizar el discurso discriminatorio sobre los chinos en Sonora, 1899-1932, para conocer los criterios con los cuales se les presentaba como seres marginales y confrontarlos con su ubicación social en la vida sonorense. Al parecer, es posible

* Agradezco a Alicia Salmerón y a Elisa Speckman el haberme sugerido trabajar este tema, la primera, $y$ a ambas por proporcionarme material útil sobre el mismo. Asimismo, a Osmar Gonzáles sus observaciones a una primera versión de este ensayo que se inició en el marco del seminario "Marginalidad y represión en América Latina", impartido por la Dra. Solange Alberro identificar una contradicción entre el discurso y la experiencia; es decir que, pese al estereotipo del chino marginal e indeseable que nos puedan arrojar los ataques en su contra, hubo un nivel considerable de integración de éste a la sociedad sonorense a finales del siglo pasado y principios del actual.

El estado de Sonora fue el que recibió el mayor flujo de migrantes chinos $y$, como contraparte, en el que la cam-

en el Centro de Estudios Históricos de El Colegio de México, de septiembre de 1994 a febrero del año siguiente. Agradezco también las útiles críticas y sugerencias de mis lectores (as) anónimos (as) de la revista Secuencia. 
paña antichina cobró mayor fuerza. Asimismo, el periodo mencionado nos permite advertir con claridad el proceso que incluye la llegada de los contingentes más numerosos hasta el origen y desarrollo de esa campaña.

Este ensayo está dividido en cuatro partes: la primera se refiere a las condiciones en que se da la inmigración china al país. La segunda está dedicada a presentar la inmigración al estado de Sonora, y el proceso de asimilación de los chinos a la sociedad de esa región. En la tercera se intenta reconstruir la imagen de "el chino" mediante la selección de cinco aspectos, que nos permiten obtener el perfil de los chinos como marginales: su comparación con animales, calidad moral, apariencia física, higiene y su actitud hacia la sexualidad. Por último, a manera de balance y consideraciones finales, se establece una comparación entre lo que se deriva del discurso, por una parte, $y$ lo que podemos advertir a partir de la realidad, por la otra.

\section{LA INMIGRACIÓN CHINA A MÉXICO}

La inmigración china a México se inició a finales del siglo XIX. ${ }^{1}$ En un prin-

1 Aunque los primeros contactos entre Nueva España y China fueron de carácter comercial -a través del galeón de Manila-, en un intercambio de mercancías chinas por plata. Los viajes del galeón a través del Pacífico se iniciaron en 1565 y concluyeron oficialmente, que no en la práctica, en 1815. Posteriormente se mantuvo la actividad comercial pero mediante embarcaciones inglesas, estadunidenses y francesas. Para mayor información sobre esta etapa en las rela. ciones sino-mexicanas, así como del proceso de negociaciones hasta la firma del Tratado de amistad, comercio y navegación con China cipio fue escasa y se dio en el contexto de la política de colonización del porfiriato (1877-1911) que, particularmente interesado en la "calidad de los inmigrantes", buscaba atraer sobre todo a europeos, blancos, católicos. Los criterios que guiaban esa preferencia eran sus supuestos "fácil asimilación, eficaz contrapeso al influjo norteamericano y belleza fisica". ${ }^{2}$

Sin embargo, aunque no en calidad de colonos, los primeros chinos que llegaron a México se incorporaron como trabajadores bajo contrato (braceros). ${ }^{3}$ Así, según datos presentados por María Elena Ota, entre 1875 y 1899 ingresaron al país 214 chinos, mientras que entre 1900 y 1910 , lo hicieron 3 442. ${ }^{4}$ Pero las anteriores cifras se quedan cortas si tomamos en cuenta que una buena cantidad de chinos

(1899), véase Valdés, Vinculaciones, 1981, pp. 53-63 y ss.

2 Ota, "Migraciones", 1993, p. 189; Valdés, Vinculaciones, 1981, pp. 81-82, y Craib III, Chinese, 1996, pp. 1-4.

${ }^{3}$ Entre 1847 y 1874 hubo un incremento mundial en el tráfico de coolies, en su mayoría chinos, que constituían mano de obra barata destinada a las plantaciones, ferrocarriles y minas. Véase Valdés, Vinculaciones, 1981, pp. 82 . 83. En México hubo señales de una temprana inmigración china en la década de 1860, pues en 1865 la primera compañía de colonización china recibió su concesión, al crear el emperador Maxiliano la Compañía de Colonización Asiática (véase Dambourges, “Anti-chinese”, 1975, p. 10), pero un mayor flujo de inmigrantes chinos sólo se registró posteriormente, en el porfiriato.

4 Véase "Inmigrantes chinos según fecha de ingreso 1875-1910", cuadro elaborado por el seminario Destino México, un estudio de las migraciones internacionales a México, siglos XIX y XX, fuente: Archivo General de la Nación, Registro Nacional de Extranjeros, México, en Ota, "Migraciones", 1993, p. 192. 
ingresaba ilegalmente al país por las costas mexicanas. ${ }^{5}$ Este tipo de operaciones significaba un negocio complementario para los vapores que transportaban mercancías. ${ }^{6}$ De'hecho, el régimen porfirista, favorable a la inversión extranjera, atrajo a México capitales procedentes de Estados Unidos, Gran Bretaña, Francia, Alemania y España; éstos fueron invertidos en ferrocarriles, minería, petróleo, plantaciones de azúcar, café, hule y plátano: donde había escasez de mano de obra, ésta se subsanaba con trabajadores chinos, que ofrecían el atractivo de prestar sus servicios a cambio de bajos salarios. ${ }^{7}$

Asimismo, el Tratado de amistad, comercio y navegación, suscrito entre

- México y China en 1899, proporcionó el marco legal para el enganche y traslado de abundante mano de obra desde Oriente. ${ }^{8}$ En suma, los inmigrantes chinos en México se concentraron en los estados norteños de Chihuahua, Coahuila, Nuevo León, Tamaulipas, Baja California Norte y Sonora, y en los sureños de Chiapas, Oaxaca y Yucatán. ${ }^{9}$

5 Incluso esas cifras contrastan con los datos proporcionados por Dambourges sobre el registro de llegadas de chinos a los puertos del Golfo y el Pacífico: entre 1884 y 1891, un total de 4108 ; entre 1892 y 1899, 4 032; entre 1900 y 1907, 18 922. Dambourges, “Anti-chinese”, 1975, cuadros A.1, A.2 y A.3, pp. 265-269.

${ }^{6}$ Monteón y Trueba, Chinos, 1988, p. 21.

${ }^{7}$ Irónicamente, los chinos se convirtieron en chivos expiatorios de problemas creados por otros extranjeros, tales como los derivados de un trato diferencial a trabajadores mexicanos y extranjeros, e injusto para los primeros, en HuDe Hart, "Sonora", 1984, p. 206; Craib III, Chinese, 1996, p. 10.

${ }^{8}$ Monteón y Trueba, Chinos, 1988, p. 22.

9 Gómez, Movimiento, 1991, p. 59; Craib III, Chinese, 1996, p. 8. Al respecto, resultan
En el caso de los estados fronterizos con Estados Unidos, esa colindancia incidió en los flujos de migrantes chinos. Se ha planteado la posible utilización de México, entre 1876 y 1940 , como vía de tránsito a ese país, ${ }^{10}$ pero las evidencias estadísticas no apoyan la idea. ${ }^{11}$ Más bien a la inversa, el periodo correspondiente a las leyes estadunidenses de exclusión de los chinos de 1882,1884 y 1892 coincidió con una época en la que en México se buscó atraer a la mano de obra china. ${ }^{12}$ También se ha hecho notar "la influencia del movimiento sindicalista estadunidense en la ideología de la revolución mexicana", en lo que a ideas y argumentos contra los chinos se refiere, ${ }^{13}$ así como de la legislación de salud pública sobre su contraparte mexicana de 1908 y la creación del Servicio de Inspección de Inmigración. ${ }^{14}$

muy ilustrativos los mapas elaborados por Dambourges sobre la población china por estados en los años de 1895, 1900, 1910,1921, 1930 y 1940. Por cierto, en los de 1921 y 1930 se advierte una similitud entre Baja California Norte y Sonora respecto a su población china, que contrasta notablemente con el de 1940 , donde se ve un drástico descenso en el segundo estado, como resultado de sus leyes de expulsión de chinos de 1932. Dambourges, "Anti-chinese", 1975, pp. 22, 26, 39, 161, 204 y 255.

${ }^{10}$ McCullough, America's, 1992, pp. [96]97; Craib III, Chinese, 1996, p. 8.

${ }^{11} \mathrm{McCullough}$ afirma que la población china en Estados Unidos era en 1880 de 100 686; en 1890,103620 ; en 1900, 85341; en 1910, 66858 , y en 1920, de 53 891. McCullough, "America's", 1992, p. 129. Es decir, que hasta 1920 no se percibe ningún incremento en las llegadas de chinos a ese país.

${ }_{12}$ McCullough, "America's", 1992, pp. 98 99; Hu-De Hart, "Sonora", 1984, p. 195.

13 Gómez, "Braceros", 1987, p. 52.

14 McCullough, "America's", 1992, p. 107. 
El movimiento armado que se desató en México en 1910 afectó a las comunidades extranjeras establecidas en el país, sin que la china fuese la excepción. El nacionalismo que promovía la mayoría de los dirigentes de la revolución mexicana incluía una buena dosis de xenofobia, debida a la identificación del régimen porfirista con la considerable influencia que habían logrado los extranjeros en la economía nacional. ${ }^{15}$ Pero no obstante los ataques contra sus personas y propiedades, en opinión de Hu-Hart, durante la revolución mexicana,

los chinos lograron expandirse demográfica y geográficamente. Mientras los sonorenses abandonaron sus hogares en masa para unirse a la revolución, los chinos permanecieron neutrales, dedicados a sus negocios y, en gran medida, aprovisionaron a los ejércitos revolucionarios. ${ }^{16}$

Resulta significativo que, tal como lo señala esta autora, la colonia china

15 Gómez, Movimiento, 1991, p. 84. Adviértase, por ejemplo, cómo en el "Programa del Partido Liberal", suscrito en 1906, entre otros por Ricardo Flores Magón (presidente), y Juan Sarabia (vicepresidente), se afirmaba que: "I a prohibición de la inmigración china es, ante todo, uná medida de protección a los trabajadores de otras nacionalidades, principalmente a los mexicanos. El chino, dispuesto por lo general a trabajar con el más bajo salario, sumiso, mezquino en aspiraciones, es un gran obstáculo para la prosperidad de otros trabajadores. Su competencia es funesta y hay que evitarla en México. En general, la inmigración china no produce a México el menor beneficio. "Programa", 1982, p. 409. Véase también Gómez, "Braceros", 1987, p. 52; Dambourges, "Anti-chinese", 1974, p. 66, y Hu-De Hart, "Sonora", 1984, p. 203.

${ }^{16} \mathrm{Hu}$-De Hart, "Comunidad", 1985, p. 195. haya alcanzado un punto alto en 1919 (6 078) en el estado, coincidiendo con los turbulentos años de la revolución. ${ }^{17}$

Durante el porfiriato se había tenido, sin embargo, una opinión muy pobre de los chinos. En las clasificaciones raciales, tan comunes en esa época, como resultado de la influencia del darwinismo social y de las ideas spencerianas, eran considerados por algunos miembros de la elite intelectual porfirista como parte de una raza inferior, "degradada y repugnante" ${ }^{18}$

Por último, un acontecimiento que traería repercusiones indirectas a la comunidad china en México fue el crack financiero de Wall Street en 1929. El cierre de fábricas en Estados Unidos implicó, entre otras cosas, el despido masivo de mexicanos, con lo cual, en 1930, 60000 de ellos tuvieron que salir de aquel país y, en 1931, otros $25000 .{ }^{19}$ Esa "repatriación" masiva afectaría principalmente a los estados de la frontera norte de México, creando una fuerte tensión-debida, sobre todo, a la falta de empleos-en el interior de la sociedad y una creciente presión sobre la población china. Lo anterior propició acciones tales como la deportación a China que, por el alto costo, fue sustituida pronto por la expulsión subrepticia a Estados Uni. dos. Además, en Sonora, se puso en práctica, en 1931, una disposición legal que obligaba a los orientales a especializarse en la venta de un solo tipo de mercancías, cuando sus establecimientos se caracterizaban preci-

17 lbid., p. 197.

18 González, "Ideas", 1988, pp. 565-583. Véase también Craib III, Chinese, 1996, p. 5.

${ }^{19}$ Monteón y Trueba, Chinos, 1988, p. 31. 


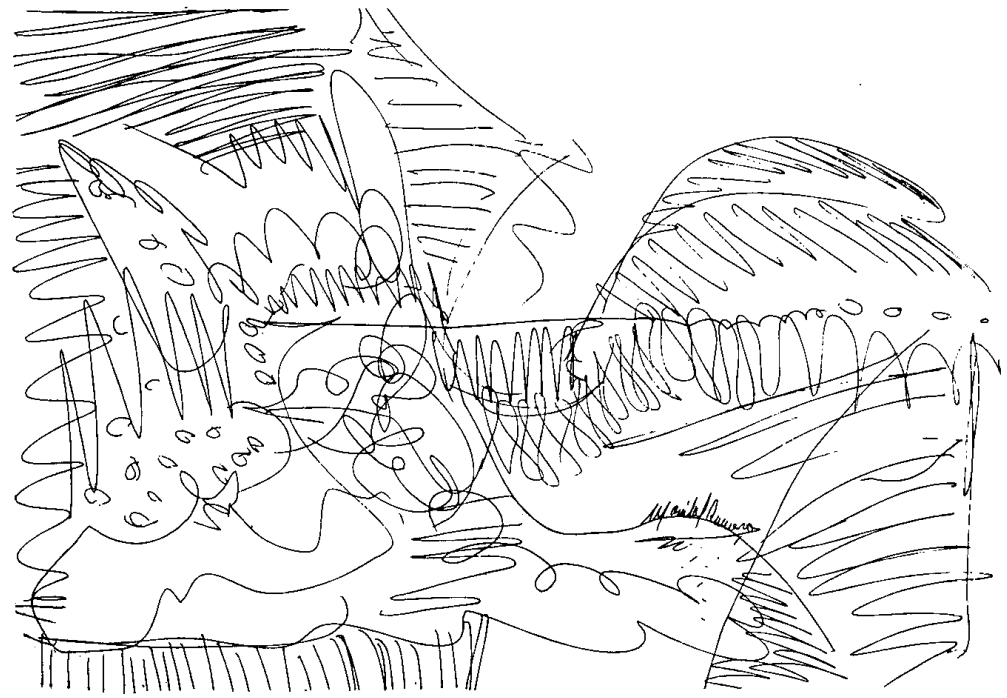

samente por la variedad de los artículos en venta.

\section{LA INMIGRACIÓN CHINA A SONORA}

De los estados de la república mexicana, el que, de acuerdo con los censos, tanto en 1895 como en 1900 y 1910 estuvo a la cabeza en la recepción de inmigrantes chinos, fue Sonora. ${ }^{20} \mathrm{El}$ de1895 registraba la presencia de 332 chinos en ese estado y el de 1900,859 ; mientras que el de 1910, presenta la

20 Véase "Inmigrantes japoneses y chinos según distribución en la república mexicana, $1895-1910^{\prime \prime}$, cuadro elaborado por el seminario Destino México, un estudio de las migraciones internacionales a México, siglos XIX y Xx, fuente: Censos mexicanos de población, 1895, 1900, 1910, en Ota, "Migraciones", 1993, p. 193. cantidad de $4486,{ }^{21}$ seguida más de cerca por Sinaloa en 1895, Chihuahua en 1900 y el Distrito Federal en 1910.

Sonora, como parte de la zona fronteriza del norte de México, significaba un campo atractivo para los chinos procedentes de Estados Unidos. La inversión extranjera en minería y ferrocarriles se traducía en prosperidad económica para la región. Además, existía una agricultura de alto rendimiento y una expansión urbana favorables al comercio. ${ }^{22}$

${ }^{21}$ De una población total en México de 12491573 en $1895 ; 13607272$, en 1900 , y 15160369 en 1910 . Véase "Población mexicana y extranjera por sexo, 1895-1910", fuente: Ma. Elena Ota Mishima. "Siete migraciones japonesas a México, 1890-1978", en Ota, "Migraciones", 1993, cuadro 1, p. 189.

22 Para un estudio más detallado sobre las 
De modo similar a lo que había acontecido en Estados Unidos con los braceros chinos, una vez que se vencían sus contratos penetraban exitosamente en el sector del comercio y los servicios, al tiempo que otros se dedicaban a la agricultura. De esa forma, a finales del siglo XIX se les encontraba desempeñándose como sastres, lavanderos, vendedores ambulantes, y vendedores de helados. A principios del $\mathrm{xx}$ los encontramos como dueños de fábricas de calzado y ropa, así como restauranteros y hoteleros. En consecuencia, los chinos favorecían un mercado interno en expansión, contribuyendo a diversificar la economía. Asimismo, la austeridad en su forma de vida y su costumbre de optimizar el espacio, al utilizar un mismo local como expendio, bodega y habitación, les permitía ahorrar en costos y les proporcionaba la posibilidad de vender más barato, ampliando de ese modo su clientela. ${ }^{23}$ Como es fácil imaginar, atrajeron al mismo tiempo la antipatía de las clases trabajadoras (al aceptar jornales bajos) y de los comerciantes locales (por la competencia que establecían con ellos). ${ }^{24}$

particularidades de esta región, véase Hu-De Hart, "Sonora", 1984, pp. 180-181, 194-196 y 205. Esta autora se refiere a una pequeña burguesía china, punto en el que coincide con Gómez Izquierdo, al identificar una "incipiente burguesía china que controlaba excedentes y realizaba inversiones en considerable escala", en Gómez, Movimiento, 1991, p. 58. También Craib III, Chinese, 1996, p. 9. 80.

${ }^{23}$ Gómez, Movimtento, 1991, pp. 63 y 79 -

${ }^{24}$ J. J. Gómez explica esa animadversión de la siguiente manera: "La movilidad social del chino aparecía como una amenaza en un medio
El norte de México, y Sonora en particular, fue escenario importante de la revolución mexicana. Este acontecimiento afectó no sólo la vida de los mexicanos, sino también la de los chinos. De hecho, las primeras expresiones antichinas se dieron en mayo de 1911, con la matanza de 303 chinos en la ciudad de Torreón, Coahuila, por las fuerzas maderistas. ${ }^{25}$ Le seguiría una serie de ataques y saqueos a esa comunidad en Chihuahua, Zacatecas, Durango, Tamaulipas y Chiapas. ${ }^{26}$

Sonora se convertiría en el bastión de las campañas antichinas. Encabezadas por un grupo de políticos y comerciantes, pronto se logró la adhesión de miembros de las clases medias y bajas. ${ }^{27}$ Figuras originarias de ese estado, que posteriormente llegarían a la presidencia de la república, tales como Plutarco Elías Calles, Adolfo de la Huerta y Álvaro Obregón, hicieron, durante su desempeño como dirigentes locales o estatales, una contribución más o menos significativa a la causa antichina. ${ }^{28}$

en el que, como extranjero con alta visibilidad sociológica, destacaba sin remedio. Al modernizar y ampliar el mercado, uniendo regiones aisladas por ejemplo, atentaba contra formas tradicionales de producción y amenazaba la inercia de una sociedad. El miedo del pequeño comerciante se expresó en un racismo antichino, era el temor de ser desplazado en la competencia económica", en ibid., 1991, p. 80.

25 Monteón y Trueba, Chinos, 1988, p. 24; Gómez, Movimiento, 1991, p. 90; González, "Xenofobia", 1969, p. 591. Para un recuento más amplio sobre estos acontecimientos, véase Puig, Entre, 1992, especialmente caps. 5 y 6.

26 Gómez, Movimiento, 1991, pp. 95-96.

27 lbid., pp. 96-97.

28 Ibtd., pp. 97 y ss. 
Dambourges distingue tres campañas antichinas en Sonora, entre 1916 y 1931, destinadas a reducir la inmigración china, debilitar su posición y promover su expulsión del estado. La primera, entre 1916 y 1921 , fue encabezada por José María Arana, pero se estrelló contra la fuerza económica y una considerable contribución en impuestos de la población china y el peculado oficial. La segunda, resultado de las guerras tong en 1922 y 1924 , tuvo un desenlace similar pues hacia 1928 los chinos controlaban más de $80 \%$ del comercio de abarrotes al menudeo, a pesar de las restricciones legales en su contra. La tercera se gestó en el contexto de la Gran Depresión y la incidencia en la economía sonorense del desempleo, el caos económico y el regreso de miles de mexicanos procedentes de Estados Unidos, a los que se agregaba la notable influencia alcanzada por los chinos en la economía de ese estado. ${ }^{29}$

La prensa sonorense, por su parte, tuvo un papel muy activo en la campaña y movilizaciones antichinas. En el semanario Toro de Once, así como en los periódicos El Tráfico, El Centenario, El Heraldo de Cananea, El Intruso, El Nacionalista y El Pueblo, los antichinos encontraron un foro eficaz desde donde difundir sus furibundos embates contra la presencia de orientales en el estado de Sonora, ${ }^{30}$ contribuyendo así a forjar una imagen sobre el chino, que es lo que trataremos a continuación.

\footnotetext{
29 Dambourges, "Anti-chinese", 1974, p. XII.

30 Trueba, "Cuestión", 1990, vol. 2, pp. 38-
} 42.

LAS CAMPAÑAS aNTICHINAS EN SONORA

\section{LA RECONSTRUCCIÓN DEL PERSONAৃJE}

\section{El chino y los animales}

El empleo de la terminología animal en el discurso tenía el objetivo de rebajar la calidad humana de los chinos. En la propaganda discriminatoria contra ellos en Sonora, es posible detectar imágenes y comparaciones recurrentes que los remiten a diversos tipos de animales. De hecho, las referencias son por lo general a animales venenosos, parasitarios o de presa.

En este sentido, en 1871, cuando la inmigración china apenas daba visos de iniciarse, ${ }^{31}$ un editorialista del periódico El Siglo Diez y Nueve, de la capital del país, ya se refería a los chinos como "esa langosta que por desgracia tiene en México algunos patronos". 32 Agregaba que sus alimentos favoritos eran "el té, el arroz, las ratas y los reptiles", es decir, animales comúnmente repulsivos o poco usuales en la alimentación de la mayoría de los mexicanos en este siglo. Algunos años más tarde, en otro editorial, esta vez del periódico $E l$ Tráfico, editado en Guaymas, Sonora, se decía que "el mongol es la hormiga de la familia humana", destacando su laboriosidad, parquedad en el comer y capacidad acumulativa ${ }^{33} \mathrm{~A}$ primera vista se podría pensar que la alusión a la hormiga es con el fin de resaltar la dedicación al

${ }^{31}$ Vid. supra.

32 Castañeda, "Editorial. Inmigración China. II", El Siglo Diez y Nueve, 24 de octubre, 1871, primera plana.

${ }^{33}$ Véase "Los chinos en México", El Tráfico, 8 de febrero de 1899 , p. 2 , reproducido por Monteón y Trueba, Chinos, 1988, p. 37. 
trabajo como una virtud de los orientales. Sin embargo, el autor no deja lugar a dudas cuando aclara que en Estados Unidos, al "mongol se le teme no tanto por sus vicios como por sus virtudes". 34

Por otra parte, en otro número de ese mismo periódico encontramos la imagen de la abeja en relación con la presteza que mostraban los chinos al acudir a las oportunidades de trabajo: en Estados Unidos, donde hacia finales del siglo XIX hacían falta trabajadores, los chinos "que se adaptan a todos los climas y a todos los trabajos, acudieron como abejas a la miel". ${ }^{35}$ También en México, "al abrirles nuestras puertas acudieron como abejas absorbiendo el hospitalario panal". ${ }^{36}$ No obstante, la experiencia mostraba, siguiendo a $E l$ Tráfico, que su presencia no era benéfica sino parasitaria para el país, comparándoseles con zánganos. ${ }^{37}$ Como a todo parásito había que combatirlo y "organizar una batida general contra los zánganos del Asia que es la peor calamidad que nos podía haber caído encima", 38 y tratar de que el comercio se levantase de nuevo "sobre los escombros de ese enjambre de parásitos". 39

El pulpo, y la idea de sus tentáculos

${ }^{34}$ Loc. cit.

35 "A propósito de los chinos", El Tráfico, 11 de febrero de 1899 , p. 2 , en Monteón y Trueba, Chinos, 1988, p. 39.

36 "Los chinos", El Tráfico, 2 de marzo de 1899 , p. 2, en ibid., p. 41.

37 "El sol chino. III", El Tráfico, 17 de marzo de 1899 , p. 1, en ibid., p. 49.

38 "Los chinos", El Tráfico, 6 de junio de 1899, p. 1, en ibid., p. 53.

39 "Sobre los chinos", El Tráfico, 6 de marzo 1989 , p. 1, en ibid., p. 42. abarcando el comercio, fue uno de los animales más utilizados por los furibundos antichinos para ilustrar el su. puesto parasitismo de sus adversarios. Lo encontramos en la mayor parte de su propaganda en Sonora. La imagen de "ese inmenso" y "asqueroso pulpo" 40 servía para esclarecer el efecto de los orientales en el ramo comercial. Asimismo, se evidenciaba la intención de presentar a los chinos como seres peligrosos, malagradecidosy, en suma, indeseables, mediante la referencia a animales repulsivos, ya fuera de presa, venenosos o transmisores de enfermedades como las ratas. ${ }^{41}$

El chino fue visto como una plaga durante toda su estancia en el estado de Sonora. ${ }^{42}$ Incluso frente a su apariencia de un ser "manso y bueno, resignado y dócil", José Angel Espino-

40 "Los chinos" y "No más chinos", El Tráfico, 2 y 8 de marzo, en ibid., pp. 41 y 43; AHSRE, 18-7.162, foja 34 ("Ante el peligro asiático", editorial firmado por Toro de Once, del semanario El Toro de Once, 30 de marzo de 1919); y AGN, Dirección General de Gobierno, D.2, ramo 31 , exp. 391, caja 20. Una consigna de la época era contra "el asqueroso pulpo que absorbe el comercio nacional".

41 "A propósito de los chinos", Monteón y Trueba, Chinos, 1988, p. 48. Es posible distinguir, por cierto, en la última frase, un ligero matiz que podría reivindicar su acción. Sin embargo, este asomo de benevolencia (en 1899) es inexistente años más tarde, en plena animadversión antichina.

42 "El comerciante chino" (pintado por $E l$ Progreso), El Tráfico, 4 de mayo, 1899, p. 3, en Monteón y Trueba, Chinos, 1988, p. 52; AHSRE, 18-7-162, foja 32 ("La ley ante el peligro chino", de "Noel Mezden" León Méndez), en El Eco del Yaqui, Semanario Independiente, Cocorit, $\mathbf{R}$. Y., 29 de marzo de 1919 (recorte de periódico); Espinoza, Efemplo, 1932, y Problema, 1931, $250 \mathrm{pp}$. 
za (diputado sonorense, miembro del Partido Nacional Revolucionario y fervoroso antichino) aclaraba que "nadie piensa en que esa mansedumbre se parece a la del gato que no desenfunda las uñas para no ahuyentar a los ratones" ${ }^{43}$ En 1924, un editorialista, el Barón $\mathrm{Ru}$, prevenía contra la supuesta lujuria del chino. Si a ello se agregaba el interés de una "inocente o perversa" niña que se dejara acariciar por él, caía inevitablemente en las "garras de la deshonra". 44

El mensaje que proyectaba este tipo de expresiones es claramente de rechazo, aversión y alerta con respecto a la presencia de los chinos. De acuerdo con este discurso, el "envenenamiento" que podían causar a la sociedad no se reducía al ámbito de la economía, sino también al de la propia integridad fisica y moral de la comunidad, en nombre de la cual pretendian expresarse los antichinos.

\section{El chino y su calidad moral}

Las objeciones al "carácter propio" de los chinos no se quedaban a nivel de las metáforas. En 1871, a través de $E l$ Siglo Diez y Nueve, ${ }^{45}$ se les echaba en cara además el ser vanidosos y supersticiosos, fatalistas, estar encerrados en su ignorancia, su degradación y soberbia, ser dóciles, pero no debido a su

43 Espinoza, Problema, 1931, p. 68.

${ }_{44}$ El Barón Ru, "Caricias de chino", El Nacionalista. Tri Semanario Pro-Raza, 25 de abril de 1924, AGN, Dirección General de Gobierno, D.2, ramo 31, exp. 391, caja 20.

45 Castañeda, "Editorial. Inmigración China, II", El Siglo Diez y Nueve, 24 octubre, 1871, primera plana. virtud, sino por abyección y cobardía, tener vicios distintivos como el juego y la embriaguez, emplear su ingenio para adquirir propiedad ajena, ser fumadores de opio y faltos de patriotismo, ${ }^{46}$ mezquinos, avaros, ${ }^{47}$ advenedizos, ${ }^{48} \mathrm{de}$ "costumbres diametralmente opuestas a las nuestras" 49 y "carentes de sentimientos humanitarios". 50

Por su parte Adolfo de la Huerta, gobernador de Sonora en 1919, los caracterizaba como "indolentes con sus semejantes, apáticos a las buenas costumbres"; insistía en su "insaciable avaricia" y nula representación social. ${ }^{51}$ Según el gobernador, los chinos además de timar a sus clientes tenían vicios degenerados y costumbres depravadas; estaban plenamente identificados en Sonora como opiómanos, marihuanos y tahúres, de tal forma que, tanto "el uso consuetudinario de sus venenosos narcóticos" como los escándalos y violencia que éstos ocasionaban, eran inevitables en virtud de que formaban "parte inherente de su sistema original de vida". ${ }^{52}$ De la Huerta reforzaba la idea del chino como "pulpo" refiriéndose a la competencia desleal que establecía con el

46 "A propósito de los Chinos", El Tráfico, 11 febrero 1899 , p. 2, en Monteón y Trueba, Chinos, 1988, p. 38.

47 "Sobre los chinos", El Tráfico, 6 marzo 1899, p. 1, en ibid., p. 41.

48 " ¡No más chinos!", El Tráfico, 7 de marzo de 1899 , p. 1 , en ibid., p. 43.

49 AHSRE, 18-7-162, foja 31 .

50 Toro Viejo, "Ante el peligro asiático", editorial firmado por "Toro de Once", del semanario El Toro de Once, 30 marzo, 1919, en AHSRE, 18.7-162, foja 34 .

${ }^{51}$ AHSRE, 18-7-162, ff. 6-7.

$52 \mathrm{Ibid}$. 
mexicano, al adulterar los productos que vendía y defraudar a los clientes en el peso de aquéllos. 53

Hacia 1930, J. A. Espinoza resume en el amor al dinero la esencia del chino; identifica en aquél el motor de todas sus acciones, lo mismo de las positivas (trabajar, pagar impuestos), como de las negativas (desobedecer las leyes, atacar la moral, sobornar, etc.) ${ }^{54}$ Otra de sus características típicas es su falta de ideales e insensibilidad ante "lo grande y lo bello", es decir, ante el arte. Presenta al chino como a un ser desalmado y perverso, capaz de fingir y "expresar, con muecas de simio de circo, el asombro que no siente y el dolor que no experimenta", ${ }^{55}$ si así conviene a sus intereses. En suma, a partir de lo anterior podemos advertir los esfuerzos de los autores por identificar en los chinos a seres éticamente reprobables, con vicios distintivos y, peor aún, irredimibles.

\section{El chino y la apariencia física}

En estrecha relación con la "calidad moral" de los chinos está su apariencia, que igualmente se convirtió en causa de repudio. En este aspecto, el leitmotiv tuvo un carácter racial: el

${ }^{53}$ AHSRE, 18-7-162, ff. 44-45.

54 "Es un enamorado fanático del dinero y este gran amor es el foco de todas sus pasiones. Por el amor al dinero piensa y trabaja; por el amor al dinero pisotea las leyes y baila una danza sobre las bases de la moral; por el amor al dinero paga impuestos y soborna a funcionarios púbiicos; por el amor al dinero soporta burlas y, en fin, por ese inmenso amor, el chino es chino". Espinoza, Problema, 1931, p. 67.

55 Ibid., p. 71. resultado de la mezcla genética con los chinos.

En 1871, El Siglo Diez y Nueve ya había alertado sobre los riesgos de la "mezcla de razas que nada tienen de homogéneo en su idioma, religión, índole, costumbres, instituciones políticas ni aun en sus vicios". ${ }^{56}$ Asimismo, se hacía notar que pese a que tenían las pretensiones de una "coqueta parisiense", la naturaleza les había privado "aun del menor atractivo". ${ }^{57}$ Años más tarde, El Tráfico expresaba la misma inquietud ante el hecho de los matrimonios de "nuestras mujeres [...] con tan raquíticos y degenerados individuos" ${ }^{58}$ Lejos de representar la "influencia regeneradora de nuestra sangre", como lo podrían ser razas "superiores" (teutónica, francesa, eslava, etc.), la combinación chino-mexicana en términos genéticos no llevaba sino a la degeneración. 59

Los chinos eran nombrados con frecuencia de un modo despectivo como "hombres de ojos atirantados", ${ }^{60}$ o que tenían "ojales en lugar de ojos", ${ }^{61}$ además de "coletudos, mugrosos, de aspecto salvaje". ${ }^{62}$ Hacia 1930, J. A. Espinoza proporciona un cuadro com-

56 Castañeda, "Eđitorial. Inmigración china. I", El Siglo Diezy Nueve, 18 octubre, 1871, primera plana.

57 Ibid.

58 "Contra los chinos", El Trafico, 11 marzo, 1899, p. 2 , en Monteón y Trueba, Chinos, 1988 , p. 45.

59 "Raza e inmigración", El Tráfico, 1 junio 1899 , p. 2, en ibid., p. 52.

${ }^{60}$ AHSRE, 18-7-162, foja 31.

61 Toro Viejo, "Ante el peligro asiático", AHSRE, 18-7-162, foja 34 .

62 General Romo, "La necia altanería de los chinos", El Intruso, 14 febrero 1924, (recorte 
pleto y deplorable del resultado de la unión de chinos y mexicanas cuando se refiere a esas "criaturas raquíticas y macilentas, anémicas y tristes, calladas y egoístas que se excluyen por temperamento del trato común de los demás niños". ${ }^{63}$

Como se puede advertir, no era la mezcla de razas en abstracto lo que se objetaba, lo cual hubiese sido evidentemente dificil de sostener en un país de población mestiza, sino la combinación de las uniones entre chinos y mexicanas, considerada a todas luces inadecuada $e$ indeseable. Para efectos del racismo contra los chinos, esa distinción salía sobrando. De hecho, pese a que a finales del siglo XIX y principios del XX era común y aceptado hablar de "razas", el solo uso recurrente del término hace pensar inmediatamente en una jerarquización de ellas.

\section{El chino y la sexualidad}

Otro aspecto que se reprochaba a los chinos era su actitud hacia el sexo. En intima relación con su proverbial lascivia y costumbres depravadas, estaba su práctica de la poligamia que, al ser permitida en su país natal, había destruido por completo el amor a la familia. ${ }^{64}$ En ese sentido, se denunciaba el que varios chinos tuviesen relaciones con una sola mujer (conocida como "chinera"). La queja de "amanceba-

de periódico), AGN, Dirección General de Gobierno, D.2, ramo 31, exp. 391, caja 20.

63 Espinoza, Problema, 1931, p. 159.

${ }^{64}$ Castañeda, "Editorial. Inmigración china. II", El Siglo Diez y Nueve, 24 octubre, 1871, primera plana.

LAS CAMPAÑAS ANTICHINAS EN SONORA miento" de más de un chino con una sola mujer reforzaba, además, su imagen de degenerado e inmoral", ${ }^{65} \mathrm{y}$ prevenía contra el riesgo de lanzar a la indigencia a los hijos de esas uniones.

Pero las acusaciones no paraban ahí. La seducción y prostitución de jovencitas mexicanas fue otro motivo de recelo contra ellos. ${ }^{66}$ De hecho, se pensaba que las mujeres recurrían a los chinos por "mal gusto o por desgracia". En este segundo caso estaban sobre todo las viudas o las mujeres de baja condición económica. La trama del argumento era bastante compleja pues presentaba, por lo general, a mujeres depauperadas por la competencia desleal de los chinos, que las desplazaban de las esferas tradicionalmente reservadas a ellas, como eran el lavado de ropa y la preparación y venta de alimentos. Una vez en la miseria, estas mujeres estaban forzadas a recurrir a ellos, con lo cual los chinos lograban un doble éxito: satisfacer sus pretensiones comerciales, sobre todo si las prostituían, y sus necesidades sexuales. ${ }^{67}$

Lo anterior, aunado a los prejuicios raciales que pesaban sobre ellos, y a la beligerancia de la campaña antichina,

65 Carta del oficial mayor de la Secretaría de Gobernación al Lic. Salvador Diego Fernández, oficial mayor $\mathrm{E}$ del Despacho de Relaciones Exteriores, en la que transcribe informes del gobernador de Sonora [Adolfo de la Huerta] acerca de los barrios especiales para los ciudadanos chinos, México, 24 de abril, 1919, en AHSRE, 18.7-162, ff. 6.7.

${ }^{66}$ AGN, Dirección General de Gobierno, D.2, ramo 31, exp. 391, caja 20: transcripción de una carta de W. Pesqueira, presidente municipal de Nogales, Sonora, 27 de marzo de 1924.

67 Espinoza, Problema, 1931, pp. 89-92. 


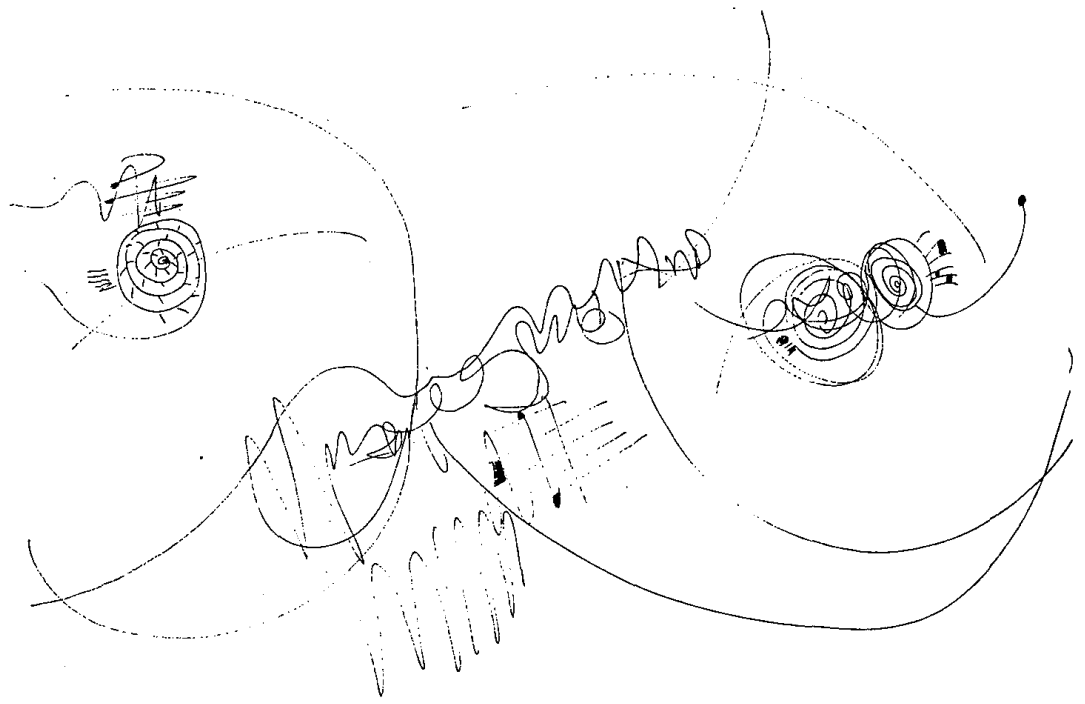

desembocó en la ley número 31 (Sonora, 20 de diciembre, 1923), que prohibía el matrimonio de mexicanas con chinos, al tiempo que castigaba con multas "la vida marital o unión ilícita entre chinos y mexicanas". ${ }^{68}$

\section{El chino y la higiene}

Bajo la premisa de que eran portadores, y por lo tanto focos de infección, de enfermedades ingénitas en ellos, tales como sífilis, lepra, tracoma, conjuntivitis granulosa y tuberculosis, en el discurso antichino se introdujeron argumentos acerca de la higiene y

${ }^{68}$ Espinoza, Ejemplo, 1932, p. 35. la salubridad. ${ }^{69}$ Así, El Tráfico se refería en 1899 a que había algunos de ellos "atacados de enfermedades sospechosas", como la lepra, por lo que se temía un contagio a la población mexicana. ${ }^{70}$ Esa situación se veía favorecida y agravada por las condiciones de sus viviendas y de sus hábitos, pues

viven aglomerados en casas suficientes apenas para albergar a la cuarta parte de

${ }^{69}$ AHSRE, 18-7-162, ff. 26-27, carta del encargado de Negocios Chinos al Lic. Salvador Diego Fernández, oficial mayor encargado de la Sria. de Relaciones Exteriores, s.l., s.f.; transcripción de carta de W. Pesqueira, AGN, loc. cit., y El Barón Ru, "Caricias de chino", loc. cit.

70 "Pro bono público" $y$ "Contra los chinos", El Tráfico, 7 y 11 de marzo de 1899 , en Monteón y Trueba, Chinos, 1988, pp. 42 y 45. 
los que en ellas habitan y tienen la pésima y reprobable costumbre de arrojar inmundicias en el interior de dichas habitaciones. ${ }^{71}$

Además, el inevitable contacto físico con los productos que vendian, sobre todo alimentos, los presentaban como un factor de contagio inminente, a tal punto que en 1924 una de las consignas de la campaña antichina en Sonora era: "Por higiene, no le compre al chino". 72

Por otro lado, con frecuencia se extiende la terminología relativa a la higiene para referirse a la "salud" de la sociedad. Es decir, se alude a la "higiene moral de los pueblos", 73 que resultaba amenazada por los chinos, o bien al "contagio" de sus costumbres que podian hacer las "chineras" prostitutas a otras mujeres, si se les desterraba a estados vecinos al de Sonora. ${ }^{74}$

Con base en lo anterior, el perfil del chino enunciado en los textos consultados corresponde al de un marginal; conjuga sentimientos y actitudes de subestima, desprecio, miedo y repulsión. Esta imagen precedió incluso su llegada al pais ${ }^{75}$ y lo acompañó duran-

${ }^{71}$ Loc. cit.

72 AGN, loc. cit.

73 "El sol chino III", en Monteón y Trueba, Chinos, 1988, p. 51.

${ }^{74}$ AHSRE, 18-7-162, foja 34. J. Gómez identifica esa tendencia a diferenciar la gente saludable de la gente enferma (en términos de moral y costumbres) como una idea fascistoide que autoriza a los primeros "a participar en la comunidad y en la construcción de una sociedad moderna $y$ fuerte (saludable) ${ }^{n}$, destinando a la vez a los enfermos y a los improductivos a ser eliminados, en Gómez, Movimiento, 1991, p. 126.

${ }_{75}$ Tal como lo hace notar Jorge Gómez Izquierdo cuando se refiere a la "primera etapa del te su estancia en el estado de Sonora hasta su expulsión en los primeros años de la década de los treinta.

\section{DISCURSO $V S$. REALIDAD}

Si contrastamos la imagen del chino como marginal a través del discurso, con su nivel de integración a la sociedad sonorense, el resultado es una evidente contradicción. Es decir, por un lado se tiene a un marginal al que se rechaza en el discurso pero, a la vez, a un individuo aceptado e integrado a la sociedad mediante el comercio y los servicios.

El comercio fue la actividad más popular entre los chinos en Sonora, a tal punto que lograron "prácticamen. te monopolizar el comercio local de alimentos, telas, ropa y mercancías en general, tanto en la venta al mayoreo como en la venta al por menor". ${ }^{76}$ Lo mismo cultivaban que transportaban sus productos (granos, frutas y vegetales) para su venta en los mercados locales. Se destacaron también en la producción de calzado y de ropa destinada a las clases bajas, "pequeños productos de piel, masa y tortillas, pastas y dulces". ${ }^{77}$

De acuerdo con datos proporcionados por Hu-De Hart acerca de la "ocupación de los chinos en Sonora", en 1919 tenemos a un total de 4258 vendedores (fijos o ambulantes), ocho industriales, 207 hortelanos, $196 \mathrm{mi}$ neros, 58 cocineros, 69 lavanderos,

prejuicio antichino en México", en "Nacimiento", 1987, p. 23.

76 Hu-De Hart, "Comunidad", 1985, p. 195.

${ }^{77}$ lbid. 
69 zapateros, tres bajo el rubro de "cantinero, joyero, curtidor", 39 panaderos, 778 jornaleros, 100 menores y 255 vagabundos. ${ }^{78}$

Pero todavía más revelador del peso de los chinos en la economía regional de Sonora es un cuadro sobre los "establecimientos comerciales y capital en Sonora" para ese mismo año, pues a los chinos correspondían 827 establecimientos, con un "capital total" de 2186935 pesosy un "promedio por establecimiento" de 2644.42 pesos, mientras que a los "mexicanos y todos los demás" correspondían tan sólo un número de 434 establecimientos con un "capital total" de 2813540 y un "promedio por establecimiento" de 6482.41 pesos. ${ }^{79}$

La "burguesía comercial china" hacia 1925 incluía a 3437 individuos, entre los cuales estaban 174 mujeres, que comprendían 1570 vendedores, 465 granjeros, 230 empleados, 98 zapateros, 37 sastres, 98 cocineros, 97 industriales, trece profesionales, 247 jornaleros, 73 lavanderos y un "capital chino invertido (en pesos)" de 1784 436, frentea 2697803 de "capital mexicano invertido (en pesos)" ${ }^{80}$

Estos datos nos muestran no sólo la competencia real que se establecía entre chinos y mexicanos, sino también el nivel de integración de aquéllos a la economía mexicana y, en virtud del tipo de actividades que desempeñaban, el necesario contacto entre ambas poblaciones.

Pero no sólo el comercio y los servicios ponían en contacto a chinos y me-

78 Ibid.

79 Ibtd., p. 200.

${ }^{80}$ Ibid., p. 202. xicanos en una relación de mutuo beneficio. En un informe, José María Pontó $^{81}$ reconocía que, si bien la actividad de la colonia china en Sonora podía haber perjudicado los intereses de los comerciantes "menos dotados para la concurrencia económica", expulsándolos de sus actividades, el estado en su conjunto se había beneficiado, en términos de un mayor abasto de productos baratos, la introducción de otros, así como por un incremento en la recaudación de impuestos. ${ }^{82}$ Por lo tanto, la imagen de los chinos como parásitos de la sociedad no resulta tan convincente. ${ }^{83}$

Hace falta un estudio demográfico que nos muestre la proporción de la población china masculina que contrajo matrimonio con mexicanas sonoren-

81 Se trataba de un funcionario de la capital del país, que había sido enviado a Sonora para tratar de que la legislatura de ese estado derogara los decretos 27 y 31 , sobre el establecimiento de barrios especiales para los chinos en cada ciudad y la prohibición de matrimonios de chinos con mexicanas. Véase [Informe] de José Mariano Pontón al secretario de Estado y del Departamento de Gobernación, 17 de mayo, 1924, AGN, Dirección General de Gobiemo, D.2, ramo 31 , exp. 391, caja 20.

82 Por ejemplo, en 1930 los chinos de Sonora respondieron a la violencia desatada en su contra "closing their stores and refusing to pay their taxes, threatening the economic stability of the state, McCullough, “America's”, 1992, p. 125.

83 Por cierto, una vez introducidos en el fangoso terreno de los estereotipos, está la opinión de Chang Yin Tang (ministro chino en Washington) sobre las clases bajas mexicanas, al señalar que a esta gente le disgustaban el trabajo, la paz, la ley y el orden. En el mismo sentido se expresó otro observador chino al referirse al control de los extranjeros sobre la industria mexicana debido a que "the mexican people are lazy and cannot well manage their own living", Dambourges, "Anti-chinese", 1974, pp. 84-85. 
ses en esa época. Se sabe, no obstante, que pocas mujeres chinas inmigraban a México, ${ }^{84}$ por lo cual es probable que esas uniones hayan sido frecuentes. Aunque sólo con carácter indicativo, tomemos, asimismo, la legislación antichina, en especial, la ley $31,{ }^{85}$ que prohibía el matrimonio de chinos con mexicanas y asignaba multas en caso de vida marital o uniones ilícitas entre unos y otras; podemos intuir detrás de esa proscripción un nivel de convivencia o contacto considerable entre ambas poblaciones, a pesar de lo que propalaba la campaña antichina. De otra forma, esa prohibición se antoja innecesaria.

Por otro lado, se tiene la aceptación de los comercios chinos por parte de la población mexicana. ${ }^{86}$ Resulta significativo, al respecto, que las "guardias verdes", o cuerpos de choque propios de la "etapa culminante" de dicha campaña (hacia abril de 1931), tuviesen como misión la de instalarse frente a las tiendas chinas para impe-

${ }^{84}$ Hu-De Hart hace notar que en el censo de 1930 sólo 412 eran mujeres, en una población total de 3471 , e incluso que no se puede tener la seguridad de que esas 412 fuesen chinas, pues "las leyes del estado de Sonora habían comenzado a despojar de su nacionalidad a las mujeres mexicanas casadas con chinos", Hu-De Hart, "Comunidad", 1985, p. 197.

85 Espinoza, Ejemplo, 1932, p. 35.

${ }^{86}$ Esta preferencia la hizo notar Juan Lung Tain al gobernador Arana, a quien además acusó de incitar a la violencia antichina apoyando así su candidatura para presidente municipal en las siguientes elecciones. Tain le hizo notar igualmente que los mexicanos preferían comprar en las tiendas chinas porque era más barato y que incluso lo hacían también las familias de los líderes de la cruzada antichina con el fin de ahorrar dinero, Dambourges, "Anti-chinese", 1974, pp. 130-131.

LAS CAMPAÑAS ANTICHINAS EN SONORA dir el acceso a sus clientes. Esto, aunado al aumento de las contribuciones que les fue impuesto, iba en detrimento de la aceptación popular de que habían gozado los comercios chinos, muy probablemente sobre todo entre la población de escasos recursos económicos y a pesar de las condenas que pesaban en su contra.

Por otro lado, por razones expositivas me he referido hasta ahora a una comunidad china aparentemente monolítica. Sin embargo, esa imagen se revela falsa a partir de 1911, cuando se implanta la república por Sun Yat Sen. En México, y concretamente en Sonora, se da una escisión en la Unión Fraternal China, que era una macroorganización que aglutinaba a asociaciones chinas con diversos intereses y era controlada por la Chee Kung Tong. Pero cuando en 1911 aparece en escena el Kuo Ming Tang, cuya sede estaba en Nogales, Sonora, sus miembros disputan y consiguen el mando de la Unión Fraternal, con la subsecuente salida de sus antiguos dirigentes. A partir de ese momento, hubo enfrentamientos constantes entre el Kuo Ming Tang y la Chee Kung Tong, cuya factura en términos de acusaciones de violencia era pagada por el resto de la comunidad china, conformada por simples ciudadanos, ajenos a la disputa. ${ }^{87}$

${ }^{87}$ Monteón y Trueba, Chinos, 1988, pp. 28 29 y Nava, Abajo, 1994, p. 161. Véase también Dambourges, "Anti-chinese", 1974, cap. 6, pp. 163-200, donde describe en detalle el desarrollo y consecuencias de esos enfrentamientos entre chinos. En 1922, la guerra tong fue utilizada por los antichinos para promover su expulsión del estado, apelando al art. 33 de la Constitución federal. En mayo de ese año, tras las disputas entre sí y el asesinato de algunos de ellos, se realizó 
En consecuencia, cualquier intento por explicar el desajuste entre discurso antichino y realidad en Sonora (1899-1932) deberá tomar en cuenta al menos dos elementos igualmente importantes: el primero es acerca de los antecedentes del estereotipo de China y los chinos. J. J. Gómez Izquierdo hace un seguimiento histórico al respecto, señalando que se inicia con la estancia de 17 años en China del comerciante veneciano Marco Polo en el siglo xIII, y los informes que proporcionó sobre ese país en su libro El millón, los viajes de Marco Polo. Posteriormente, la rehabilitación de la Gran Mura$11 a^{88}$ le valdría a China los calificativos de reclusión y atraso. En el siglo xVI y principios del xviII las empresas evangelizadoras portuguesas y españolas

una serie de arrestos, inclusive de chinos presumiblemente inocentes, ajenos a la violencia. De cualquier forma, esos acontecimientos dieron lugar a la sugerencia de restringir el libre movimiento de los chinos y a promover su expulsión. De hecho, algunos fueron realmente expulsados (181 chinos sonorenses, entre junio y agosto de 1922), pero sobre todo, la guerra tong dio la pauta para reavivar la animadversión en su contra.

${ }^{88} \mathrm{Su}$ construcción se había iniciado "al final de la época de los Estados en Lucha (402-221 a.C.)", pero "sólo después de la unificación realizada por el primer emperador Chin, en 221 a. C., se emprendió, con el respaldo humano y económico de una China unificada, la terminación de esta obra. La muralla se prolongaría desde la provincia de Kansu en el noroeste, hasta Manchuria, con una extensión de más de $2500 \mathrm{~km}$. Incorporando barreras naturales como las montañas, constituía la obra pública de mampostería más grande en los anales de la humanidad. Durante el primer siglo de la dinastía Jan, se construyó una prolongación hacia el occidente, cerrando el paso al Asia occidental. Subsecuentemente se construyeron algunos añadidos y en el siglo xvi se llevaron a cabo reparaciones", Knauth, China, 1982, pp. 28-29. en aquel país contribuyeron, como resultado del desencuentro entre culturas distintas y del deseo de imposición de la occidental cristiana sobre la asiática, a reforzar y ampliar la idea de la población china como inferior, perversa y atrasada. En el siglo XVIII y principios del XIX, pensadores de la talla de Hegel sostenían igualmente la inferioridad de China, mientras que las politicas imperialistas que padeció en el siglo XIX por parte de Gran Bretaña, Estados Unidos, Francia, etc., pretendian ser también intentos por llevar el progreso y la civilización a ese país bárbaro y atrasado. ${ }^{89}$ México tuvo que haber recibido parte de ese bagaje cultural adverso a los chinos pues, como vimos, en 1871 , antes incluso de que llegaran en gran número al país, ya se tenía una imagen acabada de ellos.

El segundo aspecto a destacar es el económico. Íntimamente ligado a la embestida de carácter racial contra los chinos está el punto neurálgico del dinero y la queja constante de la competencia que establecían con los sonorenses. No es casual, entonces, que la campaña antichina en Sonora haya sido impulsada por comerciantes y políticos locales. Está presente también el manejo y capitalización del movimiento que hicieron estos últimos al fabricar culpables, adjudicando a los chinos el origen de las crisis económicas que se presentaron..$^{90} \mathrm{El}$ resultado fue su ex-

${ }^{89}$ Gómez, Movimiento, 1991, pp. 15-37.

$90 \mathrm{Ibid}$., p. 161. Por otra parte, la defensa de los chinos ante las autoridades mexicanas federales se hacía, generalmente, a través de la Legación China en México, según se desprende de los legajos consultados en el AGN y en el AHSRE. Las quejas daban lugar a un intercambio de co- 
pulsión de los estados de Sonora, Sinaloa, Baja California norte, Chihuahua y Tamaulipas entre 1931 y $1933 .{ }^{91}$

Así, pues, una pista sugerente para entender este fenómeno la proporcionan las observaciones de Ernest Labrousse acerca de la distinta dinámica de los ritmos económicos, sociales y mentales cuando señala que "sobre lo económico se retrasa lo social y sobre lo social, lo mental". 92

En efecto, los desequilibrios sociales y económicos en Sonora sólo pueden explicar de un modo parcial el surgimiento de las campañas antichinas a principios de siglo; en particular no explican cómo se desarrollaron, ni las modalidades que presentó su discurso. ${ }^{93}$ Este último nos remite más bien al campo de las mentalidades, pues la gestación de los prejuicios y estereotipos acerca de los chinos llevó mucho más tiempo, conservándose casi como en vida latente, para hacerse evidentes cuando las tensiones sociales y económicas en Sonora, y seguramente tam. bién en otros estados y países, así lo

municados entre la Secretaría de Gobernación y los gobiernos estatales y locales, no sin una buena dosis de tensión. Sin embargo, es probable que en los archivos locales de las poblaciones sonorenses, que no me fue posible consultar, se encuentren documentos con las quejas directas de los chinos a las autoridades mexicanas, mismos que podrían resultar muy útiles para conocer su situación y modo de vida reales.

91 Gómez, Movimiento, 1991, p. 159.

92 Labrousse, "Comentarios", 1979, p. 73.

93 El discurso en las campañas racistas o xenofóbicas resulta, además, especialmente importante debido a su capacidad para exacerbar los ánimos y, en la medida en que precede a la acción, puede influir en la intensidad y alcance del ataque.

LAS CAMPAÑAS ANTICHINAS EN SONORA demandaron. En ese sentido, y paradójicamente, el discurso antichino puede resultar más revelador de las contradicciones y características de la sociedad que lo fomentó, que del carácter y temperamento de los chinos contra los cuales estuvo dirigido.

\section{ARCHIVOS}

-AGN, Archivo General de la Nación, México, Gobernación, Dirección General de Gobierno.

-AHSRE, Archivo Histórico "Genaro Estrada", Secretaría de Relaciones Exteriores, México.

\section{PERIÓDICOS}

-El Siglo Diez y Nueve, México, D.F. -El Tráfico, Guaymas, Sonora. -El Eco del Yaqui, Semanario Independiente, Sonora.

-El Nacionalista, Tri Semanario ProRaza, Cananea, Sonora.

-ElToro delOnce, Semanario, Guaymas, Sonora.

-El Intruso, Cananea, Sonora.

\section{BIBLIOGRAFIA}

-Craib III, Raymond B., Chinese immigrants in porfirian Mexico:A preliminary study of settlement, economic activity and anti-chinese sentiment, The University of New Mexico, Albuquerque, Nuevo México, 1996 (Research Paper Series, 28).

-Dambourges Jacques, L. M., "The antichinese campaigns in Sonora, México, 1900-1931", tesis de doctorado, University of Arizona, 1974.

-Espinoza, José Ángel, El ejemplo de Sonora, s.p.i., México, 1932. 
co, Editorial Porrúa, México, 1931.

-Gómez Izquierdo,Jorge, "Braceros chinos y racismo. El movimiento antichino en Sonora (1880-1934)", La cultura en México, núm. 1328, supl. de Siempre!, núm. 1786 , septiembre 16 de 1987 , pp. 51-54. "El nacimiento del prejuicio antichino en México 1877-1932", Antropología, boletín oficial del INAH, núm. 12, enero-febrero, 1987, pp. 21-25. , Elmovimiento antichino en México (1871-1934). Problemas de racis. moy de nacionalismo durante la revolución mexicana, INAH, México, 1991 (Serie Historia. Colección Divulgación).

-González Navarro, Moisés, "Las ideas raciales de los científicos, 1890-1910", Historia Mexicana, México, vol. XxxvII, núm. IV [148], abril-junio, 1988, pp. [565]-583. "Xenofobia y xenofilia en la revolución mexicana", Historia Mexicana, vol. xvilI, núm. 4 [72], abril-junio, 1969, pp. 569-613.

-Hu-De Hart, Evelyn, "La comunidad china en el desarrollo de Sonora", Historia general de Sonora. Sonora moderno: 1880-1929, Gobierno del Estado de Sonora, Hermosillo, 1985, vol. IV. , "Sonora: indians and immigrants on a developing frontier", en Thomas Benjaminy William McNellie (comps.), Other Mexicos. Essays on regional mexican history, 1876-1911, University of New Mexico Press, Albuquerque, 1984.

-Knauth, Lothar, China: ¿entgma o ignorancia?, Editorial Oasis, México, 1982 (Colección Biblioteca de las Decisiones, 2).

-Labrousse, "Comentarios sobre el texto de Jacques Le Goff", en Solange Alberro, y Serge Gruzinski, Introducción a la historia de las mentalidades. Seminario de Historia de las mentalidades y religión en el México colonial, INAH, México, 1979 (Cuaderno de Trabajo, 24).

-McCullough, Kenneth Bruce, "America's back door: Indirect international immigration via Mexico to the United States from 1875 to $1940 "$ ", tesis de doctorado, Texas A\&M University, 1992.

-Monteón González y José Luis Trueba Lara, Chinosy antichinos en México. Documentos para su estudio, Unidad Editorial de la Secretaría General de Gobierno, Guadalajara, 1988 (Colección Historia, Serie: Documentos e Investigación, núm. 34).

- Nava Nava, María del Carmen (inv., selec., y textos), Los abajo firmantes. Cartas a los presidentes, 1920-1928, Editorial Patria, México, 1994 (Libros del Rincón, SEP).

-Ota Mishima, María Elena, "Las migraciones asiáticas en México", Elpoblamiento de México. Una visión histórico-demográfica, México en el siglo XIX, Sría. de Gobernación/Conapo, México, 1993, t. III.

-Pla, Dolores etal., Extranjeros en México (1821-1990), Bibliografia, INAH, México, 1994 (Colección Fuentes).

- "Programa del Partido Liberal", en Arnaldo Córdova, La ideología de la revolución mexicana. La formación del nue. vo régimen, Ediciones Era, México, 1982 (El hombre y su tiempo).

-Puig, Juan, Entre el río Perlay el Nazas. La China decimonónica y sus braceros emigrantes, la colonia china de Torreón y la matanza de 1911, Consejo Nacional para la Cultura y las Artes, México, 1992 (Regiones).

-Trueba, José Luis, "La cuestión china. Fuentes para su estudio", Memoria del XIV Simposio de Historia y Antropología de Sonora, Instituto de Investigaciones Históricas-Universidad de Sonora, Hermosillo, Sonora, 1990, vol. 2.

, "La xenofobia en la legislación sonorense: el caso de los chinos", $\mathrm{Me}$ moria del XII Simposio de Historia y Antropología de Sonora, Instituto de Investigaciones Históricas-Universidad de Sonora, Hermosillo, Son., 1989, vol. 1.

-Valdés Lakowsky, Vera, Vinculaciones sino-mexicanas. Albores $y$ testimonios (1874-1899), unam, México, 1991. 